\title{
TELAAH WACANA IKLAN PENJUALAN RUMAH DALAM MEDIA MASSA CETAK
}

\author{
Hari Sulastri \\ Badan Bahasa \\ Pos-el: sulastrihr@gmail.com
}

\begin{abstract}
ABSTRAK
Tulisan ini membahas tentang iklan penjualan rumah di Koran Pos Kota. Selain itu, tulisan ini bertujuan untuk mendeskripsikan dan menelaah bahwa iklan penjualan rumah dapat dipandang sebagai sebuah wacana. Iklan juga merupaka salah satu saran yang digunakan untuk memberikan informasi kepada masyarakat yang memerlukannya. Iklan juga merupakan media yang menghubungkan antara pembaca dan pembuat iklan. Dalam menjalankan fungsinya iklan mempunyai caranya sendiri baik dari segi bahasa maupun strukturnya. Iklan penjualan rumah ini merupakan iklan kecil yang menarik untuk ditelaah karena memiliki kekhasan dalam penyampaiannya. Hal itulah yang melatari penulisan makalah ini. Wacana iklan kecil ini hanya terdiri dari beberapa baris. Oleh karena itu, ditulis dengan banyak menggunakan singkatan dan bahasanya juga sangat ringkas. Untuk menelaah wacana iklan kecil ini, digunakan pendekatan struktural. Berdasarkan analisis dalam pembahasan iklan kecil ini terdapat tiga bagian, yaitu bagian awal, bagian isi, dan bagian penutup. Struktur kalimat yang digunakan juga memiliki berbagai bentuk, namun pada umumnya ditulis dengan menggunakan kalimat inversi dengan kosakata verba pasif. Penulisan singkatan dan akronim terbagi dalam beberapa kelompok, namun pada umumnya tidak seturut kaidah.
\end{abstract}

\section{Kata Kunci: telaah, wacana, iklan kecil struktur, dan pemakaian bahasa}

\begin{abstract}
This paper discusses about the advertisement of home sales in Koran Pos Kota. In addition, this paper aims to describe and analyze that home sales advertising could be seen as a discourse. Advertising is also one of the means used to provide information to people who need it. Advertising is also a media that connects readers and ad builders. In performing its function ads have their own way both in terms of language and structure. This home sale ad is a small ad that is interesting to explore because it has a specificity in the delivery. That's what's behind the writing of this paper. This home sale ad is a small ad that is interesting to explore because it has a specificity in the delivery. This small ad discourse consists of only a few lines. Therefore, it is written with many uses of abbreviations and the language is also very succinct. To analyze the discourse of this small ad, a structural approach is used. Based on the analysis in the discussion of this small ad there are three parts, namely the beginning, the contents, and the cover. In the discussion of this small ad there are three parts, namely the beginning, the contents, and the cover. The sentence structure used also has various forms, but is generally written using the inversion sentence with passive verb vocabulary. The abbreviations and acronyms are divided into several groups, but generally not in accordance with the rules.
\end{abstract}

Key words: study, discourse, small advertising structure, and language usage

\section{PENDAHULUAN}

Bahasa merupakan salah satu alat untuk berkomunikasi. Sebagai salah satu alat komunikasi bahasa memegang peranan yang penting. Dengan bahasa orang dapat menyampaikan pesan, ide atau gagasan. Penyampaian informasi itu antara lain dapat dilakukan dengan menggunakan bahasa lisan dan bahasa tulis. Dengan bahasa tulis misalnya, seseorang dapat menyampaikan idea atau gagasannya melalui iklan yang termuat dalam media massa.. Iklan jual beli dalam media massa yang 
dimaksud dalam tulisan ini ialah iklan yang hanya tersusun dalam beberapa baris kecil. Dalam $K B B I$ (2014:521) iklan seperti itu dapat dikelompokkan pada iklan kecil, yaitu iklan yang dikelompokan menurut klasifikasi tertentu dan umumnya hanya seluas satu kolom (biasanya tidak menggunakan gambar).

Dari defmisi di atas jelaslah bahwa iklan memiliki fungsi utama menyampaikan infomasi tentang penawaran atau penjualan, misalnya penjualan rumah atau bangunan kepada massa. Iklan dalam hal ini menjadi alat untuk menyampaikan informasi kepada orang yang memerlukan atau orang yang sedang mencari rumah untuk membelinya. Iklan dalam bahasa tulis biasanya terstruktur dan menggunakan elemen-elemen nonverbal. Dalam menjalankan fungsi komunikasinya ini, iklan memiliki berbagai gaya, baik dalam penyajian maupun isi iklan itu sendiri. Iklan merupakan cara yang cepat dan tepat untuk membantu seseorang yang sedang memerlukan informasi tentang rumah yang akan dijual. Oleh karena itu, iklan merupakan media komunikasi yang menghubungkan antara pembuat iklan dan masyarakat pembacanya. Dalam hal ini, bahasa memegang peranan yang penting karena merupakan sarananya (sarana untuk berkomunikasi). Bahasa Indonesia sebagai bahasa nasional yang digunakan oleh masyarakat Indonesia dalam berkomunikasi, baik lisan maupun tulisan mempunyai peranan yang penting. Bahasa Indonesia sebagai sarana komunikasi tulis, antara lain tampak dalam surat kabar. Dal;am surat kabar, antara lain memuat berbagai kolom. Salah satu kolom tersebut adalah kolom yang memuat iklan. Iklan dalam surat kabar biasanya hanya menggunakan tempat sekitar empat lima baris saja. Hal ini menunjukkan bahwa iklan yang termuat dalam surat kabar ini sangat banyak dengan berbagai macam yang diiklankan. Hal yang diiklan dalam surat kabar, misalnya biro perjalanan, biro jasa, jual alat elektronik, kost, jual mobil/motor, pengobatan, percetakan, ,jual tanah, jual rumah, kontrakan, salon, dan makanan atau boga. Iklan dalam surat kabar yang hanay terdiri atas beberapa baris itu disebut juga sebagai iklan cilik.

Setiap wacana iklan cilik hanya terdiri dari dua sampai tujuh baris. Hal yang secara langsung tampak pada iklan ini adalah bahasanya sangat ringkas karena banyak menggunakan singkatan, pemenggalan, serta pelesapan-pelesapan pada unsur kalimatnya. Jika pembaca tidak melihat konteks wacananya, terkadang sulit memahami makna singkatannya. Singkatan yang digunakan terkadang hanya dipahami dan dikenali oleh kalangan terbatas, yakni pemasang iklan dan kelompok masyarakat yang berkepentingan dengan iklan itu (Arifin dkk ; 1999: 16).

Adapun iklan kecil yang dikaji dalam tulisan ini adalah berupa iklan tentang penjualan rumah. Dari segi wacana dan pemakaian bahasa iklan, iklan penjualan rumah ini sangat menarik untuk dikaji. Untuk memperjelas deskripsi data iklan tersebut, berikut ini disajikan contoh iklan tersebut.

(1) DJ RHM SHM T80/256M2T36/

250M2T80/200M2 T21/150M

T80/90M2 nego, mask kwsn BSD

ICE malEON Bm PuspitAsri

$081288495581 / 087785298002$

(2) DI JUAL Cepat Rumah 2

Lantai, di Perumahan Citra

Garden I Blok D2 No. 28 Rt.

06/16, Kalideres, lt. 210m2 
$081282288700 \backslash$

(3) DIJUAL RUMAH komp. timah

Blok BB1/7. kelapa dua depok.

LT/LB. 90/110 M2. 3kt $+1.2 \mathrm{~km}$

+ 1. dekat UI. Bundar NF. Hg.

850 jt hub. 081384681177

(4) GRIYA ALAM Sentul Bogor Lt

105, bgn $2 \mathrm{Lt}, 3 \mathrm{kmr}$,

Sertipikat, 650jt nego. Hub

0856-1600-228,

(5) RUMAH BARU tipe45 $2 \mathrm{kmr}$

Tidur harga 450jt ciracas jaktim

Hub : edy 08138296139 \&

08111688845

Kelima iklan tersebut rata-rata terdiri atas empat atau lima baris. Jika dilihat dari pengguanaan bahasanya terdapat singkatan dan pelesapan. Data itu memperlihatkan iklan penjualan rumah dengan berbagai jenis.

\section{Rumusan Masalah}

Dari data itu dapat dipahami, bahwa wacana iklan cilik tidak mempermasalahkan tingkat kebankuan dalam penulisan bahasanya. Dalam iklan cilik banyak digunakan bentuk singkat, bentuk pemenggalan, akronim, bentuk pemangkasan yang adakalanya ditemukan singkatan yang tidak mudah dipahami oloeh setiap pembacanya. Berdasarkan penggunaan bahasa seperti itu, wacana iklan tentang penjualan rumah ini ditelaah. Berdasarkan kenyataan seperti itu pula, memunculkan masalah sebagai berikut.

a. Bagaimana struktur iklan kecil penjualan rumah dalam bahasa Indonesia?

b. Bagaimana bentuk bahasa dalam iklan kecil penjualan rumah tersebut?

\section{Tujuan Penulisan}

Adapun tujuan yang hendak dicapai adalah untuk mendeskripsikan struktur bentuk wacana iklan penjualan rumah dalam bahasa Indonesia dan deskripsi bentuk bahasa pada wacana iklan penjualan rumah dalam bahasa Indonesia.

Berdasarkan kajian atau telaah wacana iklan kecil ini akan dapat diketahui model pengungkapan bahasa untuk penjualan rumah secara tertulis di media cetak.

\section{Kerangka Teori}

Kata iklan berasal dari bahasa Arab i'lān bervariasi dengan i'lan yang dipadankan dengan advertisement ( Russell, 2008: 119). Selanjutnya (Russell, 2008: 6) menyejajarkan iklan yang berpadanan dengan advertisement, berasal dari adverténsi yang berasal dari bahasa Belanda advertentie. Bahasa Belanda mengambil dari bahasa Prancis merupakan variasi dari adperténsi. 
Dalam Kamus Besar Bahasa Indonesia (KBBI, 2014: 521) iklan dimaknai sebagai 1 berita pesanan untuk mendorong, membujuk khalayak ramai agar tertarik pada barang dan jasa yang ditawarkan; 2 pemberitahuan kpd khalayak mengenai barang atau jasa yang dijual, dipasang di dalam media massa (seperti surat kabar dan majalah) atau tempat umum. Berdasarkan definisi tersebut jelaslah bahwa iklan pada dasarnya adalah sesuatu yang diberitahukan atau hal pemberitahuan. Asmah (1984) dalam Indiastini (2016) menyatakan bahwa iklan itu juga disuguhkan, ditawarkan, dan dijual

Selain sebagai alat yang digunakan untuk memberitahukan dan mengabarkan, serta sesuatu yang digunakan untuk membujuk konsomennya iklan juga merupakan sebuah wacana. Sebagai sebuah wacana, iklan memiliki struktur yang padu. Sebagai sebuah wacana yang terstruktur di dalam iklan terdapat bagan-bagian sehingga untuk menganilisnya digunakan teori struktural. Pembuat buat iklan tentu berharap bahwa apa yang diklankan atau diinformasikan akan dapat mempengaruhi dan membujuk pembacanya untuk menindak lanjuti apa yang diperlukannya dalam iklan itu. Seperti dinyatakan sebelumnya, bahwa bahasa mnerupakan bahan dasar dari iklan, dalam hal ini adalah bahasa Indonesia. Bahasa Indonesia mempunyain kaidah yang terdapat dalam pedoman ejaan. Oleh karena itu, untuk menganalisis bahasa iklan ini digunakan kaidah yang terdapat pada buku Ejaan Bahasa Indonesia (EBI; 2016). Analisis bahasa pada tulisan ini dilihat dari penulisan kata-katanya (singkatan-singkatan dan akronim), kalimat, dan strukturnya.

Pengungkapan bahasa yang terdapat dalam iklan sudah barang tentu dimaksudkan dan diharapkan dapat dipahami pembacanya. Selajalan dengan hal itu, Wijana (1996:45) menyatakan bahwa penulis iklan berusaha agar apa yang sudah diungkapkannya selalu relevan dengan konteks, jelas, dan mudah dipahami, padat dan ringkas, dan selalu pada persoalan sehingga tidak menghabiskan waktu. Dalam hal ini, kerja sama antara pembaca dan penulis sangat diperlukan agar terjalin komunikasi yang lancar.

\section{METODE}

Penlitian ini menggunakan metode yang dikemukakan oleh Sudaryanto (2015), bahwa penelitian ini dilakukan dengan jalan, penyedian data, penganalisisan data yang telah disediakan, dan penyajian hasil analisis data. Pada tahap penyediaan data terdapat proses penentuan data, pencarian data, penyeleksian data, dan pengklasifikasian data. Dalam penganalisisan data, metode kualitatif digunakan untuk melihat bentuk dan isi iklan. Pada penyajian hasil analisis data digunakan metode deskripsi. Metode dalam penelitian deskriptif adalah akumulasi data dasar dalam cara deskriptif semata-mata, tidak perlu mencari atau menerangkan saling hubnungan, mengetes hipotesis, membuat ramalan, atau mendapatkan makna dan implikasi (Yunus, 2016:212).

Data dalam tulisan ini ialah iklan kecil mengenai penjualan rumah sebanyak 35. Data penjualan rumah yang tertulis dalam bahasa Indonesia ini diambil dari Koran Pos Kota yang terbit pada tanggal 17 September 2016.

\section{PEMBAHASAN}

Wacana dalam iklan kecil ini merupakan sebuah wacana yang utuh yang direalisasikan dalam kalimat-kalimat atau kata-kata yang membawa amanat dan informasi yang lengkap. Iklan kecil penjualan rumah ini merupakan wacana kecil yang memiliki ciri khusus yang berbeda dengan iklan lainnya. Sejalan dengan namanya jumlah baris dalam iklan kecil ini terdiri atas tiga 
sampai lima baris. Demikian pula, kalimat-kalimat yang digunakan biasanya diwarnai dengan kata-kata yang penuh dengan singkatan. Hal itu dilakukan untuk penghematan dalam biaya dan tidak banyak memakan tempat yang banyak dalam Koran yang memuatnya. Yang perlu diperhatikan juga, pada umumnya iklan baris tidak memperhatikan kaidah penulisan atau pemakaian ejaan. Meskipun begitu, dalam iklan kecil ini juga memiliki struktur yang terdiri atas bagian-bagian. Hal itu dapat dipaparkan dengan analisis mengenai wacananya antara lain meliputi, kalimat serta kosakata yang terdapat pada iklan kecil penjualan rumah di harian Pos Kota tersebut.

\section{Bagian-Bagian Wacana Iklan Cilik Rumah Dijual}

Iklan kecil sebagai sebuah struktur wacana memiliki bagian awal. Bagian awal pada iklan kecil memiliki fungsi sebagai pembuka wacana (Baryadi, 2002: 14). Untuk dapat mengetahui hal apa saja yang terdapat pada bagian awal iklan cilik penjualan rumah itu, dapat dicermati pada data berikut ini.

\section{Bagian Awal}

Sebagai sebuah struktur wacana, iklan cilik memiliki bagian awal. Bagian awal berfungsi sebagai pembukan wacana (Barjadi ; 2002:14).

(6) GRIYA ALAM Sentul Bogor Lt

105 , bgn $2 \mathrm{Lt}, 3 \mathrm{kmr}$,

Sertipikat, 650jt nego. Hub

0856-1600-228

(7) TOWNHOUSE ALAM kencana

Cmnggis Dpk. Lt142/125. Huk.

Bgn br. Clstr. Kol.rng.Pggr

Tol Cijago. Dkt Cbbr Junction.

S.huni. 1.950jtNg. 08111

871118

(8) PERCETAKAN NEGARA, Depan Hotel Purijaya. T/B: 222/180, SHM Rp. 2,5 M, 7 Kt, Cocok dijadikan Kost2-an, Hub: 0813. 8009. 9544 / WA. 0818 162. 849

(9) DJ RHM SHM T80/256M2T36/ 250M2T80/200M2 T21/150M T80/90M2 nego, mask kwsn BSD malEON Bm PuspitAsri $081288495581 / 087785298002$ 
(10) JUAL CPT BU Bukit Cimanggu

City Dlm Cluster Greendland.

Bogor. LT/LB 105/45, 2 KT

1KM, listrik 2200, PDAM,

H.540Jt nego. 081311488496

(11) TERMURAH DIBINTARO Cluster

Mwh 2 Lt Cuma 550Jt Stgs \&

Anti Bjr Dkt Psr Segar Graha

RyBintaro Unit Terbts NonKPR:

0815979758 / 081318912388

Bagian awal pada data (6) diawali dengan kata GRIYA ALAM Sentul Bogor Lt 105, bgn 2 Lt. yang ditulis tanpa menuliskan secara eksplisit bahwa rumah tersebut dijual. Bagian awal dari iklan tersebut hanya menyatakan tempat keberadaan rumah yang akan dijual. Di samping itu, iklan pada data (6) juga menyatakan ukuran yang berkaitan dengan luas tanah dan bangunan. Hal itu berbeda dengan iklan pada data (7) dan (8). Bagian awal pada kedua iklan (data 7 dan 8) penulis iklan hanya menuliskan letak rumah yang akan dijual tanpa memberikan ukuran tanah dan bangunannya. Berbeda pula dengan bagian awal pada data (9) dan (10). Kedua data (9 dan 10) pada bagian awal menyatakan secara eksplisit mengenai penawaran penjualan rumah dengan kata dijual dengan berbagain variasianya, misalnya dengan menyatakan dijual cepat butuh uang atau hanya dituliskan dijual rumah dengan ukuran, dan daerah atau tempat keberadaan rumah tersebut. Berbeda pula dengan data (11) pada data ini, pada bagian awal iklan penjualan rumah diawali dengan kosakata yang menarik pembeli dengan kosakata termurah .

Dari data tersebut setidaknya tampak bahwa bagian awal dari iklan penjualan rumah tidak selalu dimulai dengan kosakata dijual atau jual. Wacana iklan penjualan rumah dalam hal ini dapat menggunakan kosakata yang eksplisit atau implisit. Hal itu dapat dilihat pada data berikut.

(12) RMH SIAP pki 111/60m2, Hlm40m2 Vila Surya AA1 no11

Cileungsi , 165jt (disc10jt yg byr

Tnd jd 5jt sblm tgl 19sept)

$081382195599 \mathrm{kpr}$

(13) ADA TOWN HOUSE (Baru)

Di Rempoa Bintaro/dkt MRT-

PIM, Lt 120/95m2SHM-IMB; 3

$+1 \mathrm{Kt}, 3 \mathrm{Km}$ Granit / Parquet

Rp 1,2Mil*0855 135999 (bs

$\mathrm{KPR})$ 
Seperti halnya data (6, 7, dan 8), data (12) dan (13) menunjukkan bahwa pada bagian awal dari data tersebut iklan tidak memperlihatkan kata dijual. Namun menggunakan kosakata yang menunjukkan tempat atau daerah di mana rumah yang akan dijual itu. Selain itu, iklan penjualan rumah iu juga diawali dengan kosakata rumah sia huni, ada town house (Baru). Hal itu menunujukan bahwa iklan kecil penjualan rumah tidak selalu memiliki bagian awal yang menunjuk pada penawaran penjualan bagian intinya, tetapi ditunjukan tentang adanya rumah yang akan dijual. Data-data tersebut tidak mengeksplisitkan kata penjualan rumah. Pada data itu pengiklan rumah meyebutkan langsung bahw ada town house, rumah sia huni. Pada data tersebut juga menyebutkan lokasi rumah yang akan dijual itu.

Berdasarkan pada data tersebiut di atas, dapat dikatakan bahwa pada iklan penjualan rumah, pada bagian awal ini terdapat ada bentuk atau model, yaitu (1) iklan penjualan rumah yang menggunakan kata dijual rumah, dijual cepat butuh uang; (2) iklan yang menyebutkan nama lokasi atau tempat rumah yang akan dijual, misalnya Griya Alam Sentosa Sentul, Percetakan Negara depan Hotel Puri Jaya, Townhouse Alam Kencana Cimanggis Depok; (3) iklan penjualan rumah yang menunjukan kesiapan rumah rumah yang akan dijual untuk dapat segera dimanfaatkan, misalnya dengan menggunakan kosakata rumah siap pakai, rumah siap huni; dan (4) iklan penjualan rumah yang memberikan informasi bahwa rumah yang akan dijual termurah di lokasinya, misalnya termurah di Bintaro cluster mewah .

\section{Bagian Isi}

Bagian isi dari iklan penjualan rumah ini merupakan bagian yang menjadi pokok atau inti dari iklan penjualan ini. Baryadi (2002:14) menyatakan bahwa bagian isi berfungsi sebagai pemapar isi iklan. Dalam iklan penjualan rumah ini dipaparkan tentang berbagai macam rumah yang ditawarkan kepada orang yang akan membeli rumah. Rumah tipe berapa, terletak di di mana, yang ditawarkan kepada konsumen, misalnya T80/256 ${ }^{2}$, T36/250M ${ }^{2}$, T80/200M ${ }^{2}$, T21/150M ${ }^{2}$, T80/90M2 , Lt 105, bgn 2 Lt , 3 kmr, Sertipikat, 650jt. Oleh karena itu, jika inti dari iklan kecil itu membicarakan hal yang berkaitan dengan penjelasan rumah yang akan dijual, maka bagian bagian inti iklan kecil ditempatkan sesudah bagian awal. Berikut ini contohnya.

\section{(14) DJ RHM SHM T80/256M2T36/ 250M2T80/200M2 T21/150M T80/90M2 nego, mask kwsn BSD malEON Bm PuspitAsri $081288495581 / 087785298002$}

(15) BU Bukit Cimanggu City Dlm Cluster Greendland. Bogor. LT/LB 105/45, 2 KT 1KM, listrik 2200, PDAM, H.540Jt nego, 081311488496

(16) TOWNHOUSE ALAM kencana Cmnggis Dpk. Lt142/125. Huk. 


\author{
Bgn br. Clstr. Kol.rng.Pggr \\ Tol Cijago. Dkt Cbbr Junction. \\ S.huni. 1.950jtNg. 08111871118
}

(17) SAWANGAN JUAL rhm mnmls

Siap huni SHM msk mbl LT

100M LB $70=350$ jt nego, bbs

Bjr \&rmai, 100 m ke ANGKOT

0896-9137-5045, 0812-9493-7597

(18) DIJUAL BU Rumah tingkat

Di komp ANGKASA PURA

Jl Industri Kemayoran Jakpus, SHM 4kt, carport. NJOP 793jt

Hub: 0818831281

Bagian isi data iklan kecil (14) penawaran penjualan rumah dengan berbagai tipe dapat dinego, masuk kawasan BSD, mal EON, Bumi Puspitek Asri. Pada bagian isi contoh tersebut banyak informasi yang diberikan, selain berbagai tipe rumah juga tempat dan lingkungan rumah yang ditawarkan tersebut. Data (15) berisi informasi mengenai letak rumah, jumlah ruangan, daya listrik, falisitas air, dan harga yang masih dapat dinego. Data (16) berisi informasi mengenai ukuran tanah dan bangunan, bangunan baru, kluster, dan informasi tentang berbagai kemudahan yang didapat, misalnya dekat jalan tol, dekat dengan mal, rumah siap huni, informasi harga yang masih dapat dinego. Data (17) berisi informasi selain, ukuran tanah dan bangunan, juga informasi mengenai spesifikasi bangunan (minimalis) dan siap huni, keadaan lingkungan bebas banjir, ramai, serta hanya $100 \mathrm{~m}$ dari moda angutan kota. Data (18) berisi informasi mengenai bangunan, letak rumah yang akan dijual, sertifikat kepemilikan, fasilitas yang dimiliki rumah, misalnya carport, dan informasi mengenai NJOP tanah di wilyah tersebut.

Berdasarkan contoh di atas, dapat diketahui bahwa bagian isi penjualan rumah dapat berupa paparan informasi tentang ukuran tanah dan bangunan, letak (alamat) rumah yang ditawarkan, spesifikasi banguanan, fasilitas likungan, fasilitas rumah, dan kemudahan yang dapat diperoleh oleh pembeli. Selain itu juga, informasi tentang harga yang masih dapat dinego, serta NJOP di tempat tersebut. Informasi tiap-tiap iklan penjualan rumah tersebut tidak sama dalam pemaparannya. Ada yang dipaparkan secara lengkap dan jelas, namun ada pula yang hanya dipaparkan secara singkat saja, misalnya pada contoh data (18).

\title{
Bagian Penutup
}

Bagian penutup wacana iklan kecil penjualan rumah ini biasanya hanya berisi nomor telepon yang dapat dihubungi, jika ada yang berminat untuk membeli rumah yang ditawarkan tersebut. Hal itu agar orang yang berminat untuk membeli rumah dapat menghubungi pada nomor telpon yang dituliskan. Selain itu, orang yang berminat untuk membeli rumah yang 
diiklankan untuk mendapatkan penjelasan lebih lanjut tentang hal yang berkaitan dengan rumah akan dijual. Bentuk bagian penutup iklan penjualan rumah tersebut ada bermacam-macam. Misalnya sebagai berikut.

(19) PERCETAKAN NEGARA,

Depan Hotel Purijaya. T/B:

222/180, SHM Rp. 2,5 M, 7 Kt,

Cocok dijadikan Kost2-an, Hub:

0813. 8009. 9544 / WA. 0818

162. 849

(20) BU: RMH $1 \frac{1}{12}$ lt Kebagusan

Ry, Langgar III SHM, 90/140,

4.400watt, $4 \mathrm{KT}, 2 \mathrm{KM}, 3 \mathrm{AC}$ bisa

Buat kos 12KT cek http://bit. Ly/

2aHUOem MS/WA 081389438270

(21) JUAL RUMAH 2 LT Jl. Pacuan

Kuda Raya Pulomas Jak Tim Lt/

Lb. 450m2/600m2, SHM, Kt 6,

Km 5, Dpr 2, Garsi, 4Mbl. PLN

4500W. Tdk Banjir. 08129905560

(22) DIJUAL: RMH Lt260, Lb200,

SHM, Jl. Cilincing Pagi Jak-

Utara, Cck Usaha/RT, msk mbl,

50m dr J1 Raya, H. 1, 45M,

Pemilik: 081311558789, Tp

Pada data (19), bagian akhir dari iklan penjualan rumah berupa nomor telpon dan WA saja. Data (20) penjual memberikan alamat laman untuk mengeceknya, serta nomor telpon seluler dan Whats App (WA) yang dapat dihunbungi, jika ada yang berminat untuk membeli atau mencari informasi tentang rumah tersebut. Data (21), di samping memberikan informasi nomor telepon seluler yang dapat dihubungi peminatnya juga memberi informasi bahwa rumah yang akan dijual bebas dari banjir. Data (22) bagian penutupnya memberikan informasi nomor telepon selulr pemilik rumah yang akan dijual tersebut.

Dari informasi pada bagian akhir atau pada bagian penutup dapat diketahui dengan jelas bahwa penawaran yang dilakukan oleh penjual rumah yang akan dijual meliputi nomor telpon seluler yang dapat dihubungi, pemberitahuan daerah yang tidak banjir. Selain itu, juga pemberitahuan alamat email, seperti cek http://bit. Ly/2aHUOem. Dari informasi penutup tersebut setidaknya penjual atau penulis iklan berharap dapat menemukan pembeli atau peminat rumah yang serius dengan mempertimbangankan hal-hal yang diinformasikan tersebut. 


\section{Struktur Kalimat}

Seperti halnya penelitian yang pernah dilakukan oleh Indiastini (2016) yang meneliti tentang iklan kecil lowongan pekerjaan, kalimat dalam iklan kecil yang berkaitan dengan penjualan rumah ini merupakan kalimat kompleks. Pemakaian tanda baca dan banyak terdapat pelesapan bagian-bagian kalimatnya. Oleh karena itu, untuk dapat memahami wacana itu peminat rumah atau pembanca iklan ini harus dapat pula memahami konteks iklan kecil ini. Misalnya dapat ditunjukkan dengan contoh berikut.

(23) DIJUAL RUMAH Jl. Petojo

Selatan IV, Luas Tanah 87M2,

SHM, Jakarta Pusat Hub:

08167005688

(24) DJ RHM SHM T80/256M2T36/

250M2T80/200M2 T21/150M

T80/90M2 nego, mask kwsn BSD

malEON Bm PuspitAsri

(25) DIJUAL: RMH Lt260, Lb200,

SHM, Jl. Cilincing Pagi Jak-

Utara, Cck Usaha/RT, msk mbl,

50m dr J1 Raya, H. 1, 45M,

Pemilik: 081311558789, Tp

(26) JUAL CPT (BU): RMH Mmah

Klp. Gding Permai, 2LT, 6Km, 4Kmd, LT/LB = 224/400, 8 AC, (1m diatas Jln), Apsa Bank 5,7 M

Jual 4,9 M. 081329462999

(27) JUAL RUMAH 2 LT Jl. Pacuan

Kuda Raya Pulomas Jak Tim Lt/ Lb. 450m2/600m2, SHM, Kt 6, Km 5, Dpr 2, Garsi, 4Mbl. PLN

4500W. Tdk Banjir. 08129905560

Dari keempat data tersebut, dapat dikatakan bahwa iklan penjualan rumah ini menggunakan kalimat pasif. Hal itu dapat dilihat dari pemakaian verba yang berawalan di-, yaitu dijual dan yang terdapat pada awal kalimat. Kalimat pada iklan penjualan rumah ini juga dapat dikatakan merupakan kalimat inversi, yaitu diawali dengan verba mengawali kalimat, misalnya dapat dilihat pada data (26 dan 27). Selain bersusun inversi dan berupa kalimat pasif dalam iklan penjualan rumah ini juga terdapat bentuk struktur kalimat yang berstruktur tidak informatif secara semantis, misalnya pada data (28) berikut. 
(28) SAWANGAN JUAL rhm mnmls

Siap huni SHM msk mbl LT

100M LB $70=350$ jt nego, bbs

Bjr \&rmai 100 m ke ANGKOT

0896-9137-5045, 0812-9493-

7597

Selain itu, juga terdapat kalimat dengan struktur yang terdiri atas subyek dan pelengkap saja, tanpa predikat, misalnya pada data (29) berikut.

(29) PERCETAKAN NEGARA,

Depan Hotel Purijaya. T/B:

222/180, SHM Rp. 2,5 M, 7 Kt,

Cocok dijadikan Kost2-an, Hub:

0813. 8009. 9544 / WA. 0818

162. 849

Dalam iklan penjualan rumah ini, juga terdapat struktur yang hanya berupa frasa saja, misalnya pada contoh data ( 30,31 , dan 32) berikut.

(30) TOWNHOUSE ALAM kencana

Cmnggis Dpk. Lt142/125. Huk.

Bgn br. Clstr. Kol.rng.Pggr

Tol Cijago. Dkt Cbbr Junction.

S.huni. 1.950jtNg. 08111

871118

(31) TERMURAH DIBINTARO Clus-

Mwh 2 Lt Cuma 550Jt Stgs \&

Anti Bjr Dkt Psr Segar Graha

RyBintaro Unit Terbts NonKPR:

0815979758 / 081318912388

(32) RUMAH BARU Minimalis dlm

Cluster di Rawamangun, Strgs,

Bbs banjir. LT/LB: 93/110m2

21/2 lantai, 5KT, 4KM, Hrg

1,9M. $0817460788-0813$

12341425

(32) RMH SIAP pki 111/60m2, 1Hlm40m2 Vila Surya AA1 no11

Cileungsi , 165jt (disc10jt yg byr

Tnd jd 5jt sblm tgl 19sept). 
$081382195599 \mathrm{kpr}$

\section{Penulisan Singkatan dan Akronim}

Akronim dan singkatan merupakan salah satu yang diatur dalam Pedoman Ejaan Bahasa Indonesia, 2016 (EBI; 2016). Akronim dapat dimaknai sebagai kependekan yang beupa gabungan huruf atau suku kata atau bagian lain yang ditulis dan lafalkan sebagai kata yang wajar (KBBI; 2011:29). Adapun singkatan dapat dimaknai sebagai hasil menyingkat (memendekan) berupa huruf atau gabungan huruf (KBBI; 2011:1313). Dalam EBI (2016: 26-28) penulisan singkatan dan akronim, antara lain disebutkan sebagai berikut.

\section{Singkatan}

(1a) Singkatan yang terdiri atas huruf awal setiap kata nama lembaga pemerintahan dan ketatanegaraan, lembaga pendidikan, badan atau organisasi, serta nama dokumen resmi ditulis dengan huruf capital tanpa tanda titik.

(1b) Singkatan yang terdiri atas huruf awal setiap kata yang bukan nama diri ditulis dengan huruf kapital tanpa tanda titik (misalnya, SD, KTP, SIM);

(2) Singkatan yang terdiri atas tiga huruf atau lebih diikuti dengan tanda titik (misalnya, hlm., dll., dsb);

(3) Singkatan yang terdiri atas dua huruf yang lazim dipakai dalam surat-menyurat masing-masing diikuti oleh tanda titik.

(4) Lambang kimia, singkatan satuan ukukuran, takaran, timbangan, dan mata uang tidak diikuti tanda titik.

(5) Akronim nama diri yang terdiri atas huruf awal setiap kata dirulis dengan huruf capital tanpa tanda titik.

(6) Akronim nama diri yang berupa gabungan suku kata atau gabungan huruf dan suku kata dari deret kata ditulis dengan hruf awal kapital.

(7) Akronim bukan nama diri yang berupa gabungan huruf awal dan suku kata atau gabungan suku kata ditulis dengan huruf kecil.

Dalam iklan penjualan rumah ini banyat terdapat singkatan dan akronim. Hal itu dimungkinkan karena untuk penghematan biaya pencantuman iklan dalam media massa tersebut. Singkatan dan akronim dalam iklan penjualan rumah dapat dikelompokan sebagai berikut.

(1) Satu kata yang terdiri dari dua suku kata disingkat menjadi satu huruf yang terletak di awal kata.

Misalnya: harga $\rightarrow$ h; hanya $\rightarrow$ h; meter $\rightarrow \mathrm{m}$; miliar $\rightarrow \mathrm{m}$; siap $\rightarrow \mathrm{s}$; tanah $\rightarrow \mathrm{t}$. Selain itu ada juga satu kata yang disingkat dengan menggunakan huruf capital, seperti U/ $\rightarrow$ ukuran

(2) Satu kata yang terdiri atas dua suku kata disingkat menjadi dua huruf konsonan.dan huruf vokal konsonan. 
Misalnya: Jalan $\rightarrow \mathrm{Jl}$; dijual $\rightarrow \mathrm{Dj}$; juta $\rightarrow$ jt; dari $\rightarrow$ dr; harga $\rightarrow \mathrm{Hg}$; ukuran $\rightarrow$ uk; Bisa $\rightarrow$ bs, raya $\rightarrow$ Ry; gang $\rightarrow$ Gg

(3) Satu kata yang terdiri atas dua suku, tiga suku, empat suku, dan seterusnya disingkat dengan cara bagian belakang suku katanya sehingga tinggal dua huruf, tiga huruf, empat huruf atau lima huruf bagian depannya.

Misalnya: atas $\rightarrow$ ats; bayar $\rightarrow$ byr; milyar $\rightarrow$ mil; belakang $\rightarrow$ blk; halaman $\rightarrow$ hlm; tanggal $\rightarrow$ tgl; rumah $\rightarrow$ rhm; bangunan $\rightarrow$ Bgn; dekat $\rightarrow$ DKT; hubungi $\rightarrow$ Hub; pakai $\rightarrow$ pki; mewah $\rightarrow$ mwh; jln $\rightarrow$ jalan; cepat $\rightarrow$ cpt; alternatif $\rightarrow$ alt; dalam $\rightarrow$ dlm; harga $\rightarrow$ hrg; Cibubur $\rightarrow$ cbb; kamar $\rightarrow$ kmr

(6) Satu kata yang terdiri atas empat suku disingkat menjadi tiga huruf konsonan, yaitu konsonan awal suku pertama, ketiga, dan keempat.

Misalnya : Surabaya $\rightarrow$ Sby

(7) Satu kata yang terdiri atas dua suku disingkat menjadi tiga huruf, yaitu konsonan bagian awal suku pertama, konsonan bagian awal suku kedua, dan konsonan bagian penutup suku kedua.

Misalnya :butuh $\rightarrow$ bth; tidur $\rightarrow$ tdr; cepat $\rightarrow$ cpt; bawah $\rightarrow$ bwh; dalam $\rightarrow$ dlm; lengkap $\rightarrow$ lkp; bulan $\rightarrow$ bln; makan $\rightarrow$ mkn; harus $\rightarrow$ hrs; hasil $\rightarrow$ hsl; bonus $\rightarrow$ bns; tidak $\rightarrow$ tdk; kirim $\rightarrow$ krm; paling $\rightarrow$ plg; orang $\rightarrow$ org; penuh $\rightarrow$.pnh;

(8) Satu kata yang terdiri atas tiga suku disingkat menjadi empat huruf.

Misalnya: kawasan $\rightarrow$ kwsn; September $\rightarrow$ Sept; sebelum $\rightarrow$ sblm; lingkungan $\rightarrow$ Ling; kawasan $\rightarrow$ kwsn; strategis $\rightarrow$ stgs; Cibubur $\rightarrow$ Cbbr; Gading $\rightarrow$ gding; pagar $\rightarrow$ pggr; ramai $\rightarrow$ rmai;

(9) Satu kata yang terdiri atas dua suku disingkat menjadi tiga huruf, yaitu tiga konsonan bagian awal suku pertama, konsonan penutup suku pertama, diikuti konsonan bagian awal suku kedua.

Misalnya: tanggal $\rightarrow$ tgl; kamar $\rightarrow$ kmr; bebas $\rightarrow$ bbs; cepat $\rightarrow$ cpt; pasar $\rightarrow$ psr; lengkap $\rightarrow$ lkp; penuh $\rightarrow$ pnh; pintu $\rightarrow$ pnt; boleh $\rightarrow$ blh; tanah $\rightarrow$ tnh; cocok $\rightarrow$ cck; masuk $\rightarrow$ msk; tidak $\rightarrow$ tdk; kamar $\rightarrow$ kmr; dapur $\rightarrow$ dpr; murah $\rightarrow$ mrh

(10) Satu kata yang terdiri atas dua suku disingkat menjadi empat huruf konsonan dan vokal.

Misalnya: banjir $\rightarrow$ bnjr; kompleks $\rightarrow$ komp; discon $\rightarrow$ disc; masuk $\rightarrow$ mask; September $\rightarrow$ Sept; sebelum $\rightarrow$ sblm; kawasan $\rightarrow$ kwsn; lingkungan $\rightarrow$ ling; Cibubur $\rightarrow$ cbbr; strategis $\rightarrow$ stgs

(11) Satu kata yang terdiri atas dua suku disingkat menjadi lima huruf, yaitu tiga konsonan bagian awal suku pertama, konsonan penutup suku pertama, diikuti konsonan bagian awal suku kedua.

Misalnya: minimalis $\rightarrow$ mnmlis; strategis $\rightarrow$ strgs; Cimanggis $\rightarrow$ Cmnggis; terbatas $\rightarrow$ terbts; Cluster $\rightarrow$ Clstr; kontrakan $\rightarrow$ kntrkn; parkir $\rightarrow$ prkir

(12) Dua kata yang terdiri atas empat suku disingkat dengan menggunakan huruf konsonan yang diambil dari konsonan awal huruf pertama setiap kata.

Misalnya : Luas tanah $\rightarrow$ Lt; Luas bangunan $\rightarrow$ Lb; Ruang tamu $\rightarrow$ Rt; kamar tidur $\rightarrow \mathrm{Kt}$; Ruang keluarga $\rightarrow$ Rk; Kamar mandi $\rightarrow \mathrm{Km}$; butuh uang $\rightarrow \mathrm{BU}$

(13) Tiga kata yang terdiri lima suku kata atau lebih disingkat dengan menuliskan huruf pertama pada setiap kata. 
Misalnya: Pondok Indah Mall $\rightarrow$ PIM; Perusahaan Listrik Negara $\rightarrow$ PLN; Sertifikat Hak Milik $\rightarrow$ SHM; izin mendirikan bangunan $\rightarrow$ IMB; Kredit Kepelikan Rumah. $\rightarrow \mathrm{KPR}$.

\section{Akronim}

Akronim yang terdapat pada iklan penjualan rumah ini dapat dipaparkan, antara lain sebagai berikut:

Jakpus $\rightarrow$ Jakarta Pusat

Jaktim $\rightarrow$ Jakarta Timur

Jaksel $\rightarrow$ Jakarta Selatan

nego $\rightarrow$ negosiasi

Berdasarkan data yang terpapar di atas dapat dikatakan bahwa penulisan bentuk penyingkatan pada iklan penjuaalan rumah ini ini ada yang mengikuti kaidah dalam $E B I$, tetapi banyak pula yang tidak seturut dengan kaidah yang terdapat dalam EBI. Begitu pula dengan penulisan kata yang digunakan dalam iklan penjualan rumah ini, misalnya penulisan kata sertipikat yang tidak sesuai dengan kaidah penulisan penyerapan bahasa Undonesia yang terdapat di EBI. Kata certificate yang berasal dari bahasa Inggris diserap kedalam bahasa Indonesia menjadi sertifikat. Hal itu dapat dikatakan sebagi bentuk penyimpangan terhadap kaidah bahasa Indonesia yang terdapat dalam $E B I$.

\section{SIMPULAN}

Dari telaah wacana iklan kecil penjualan rumah tersebut dapat disimpulkan bahwa dari struktur kebahasaan pada bagian-bagian pembangun iklan kecil ini, secara eksplisit pada bagian awal dinyatakan dengan kata yang secara eksplisit menunjukkan bahwa rumah tersebut dijual. Misalnya dengan pernyataan dijua rumah, jual cepat butuh uang,, dijual rumah sertifikat hak miilik, rumah dijual butuh uang, sawangan jual rumah, dijual tanpa perantara rumah, Sawangan jual rumah. Selain itu terdapat pula pernyataan pejualan rumah yang dinyatakan secara implisit, misalnya rumah siap pakai, butuh uang, termurah di Bintaro, Griya Alam Taman golf, ada town house (baru), rumah baru. Pada bagian isi berisi informasi mengenai tipe rumah yang akan dijual, ukuran, dan letak rumah yang akan dijual. Bagian akhir berisi alamat atau nomor telpon, dan alamat email yang dapat dihubungai oleh orang yang berminat membeli rumah. Selanjutnya, pembahasan terhadap kalimatnya dapat dikatakan bahwa pada iklan kecil ini banyak terdapat pelesapan unsur-unsur kalimatnya. Selain itu, terdapat pula kalimat yang bersusun inversi dan berupa kalimat berpredikat verba pasif dan ada pula bentuk struktur kalimat yang berstruktur tidak informatif secara semantik.. Dari segi kosakata yang digunakan pada umumnya iklan ini banyak menggunakan kosakata yang banyak menggunakan berbagai bentuk singkatan dan akronim. Namun, kebanyakan bentuk singkatan dan akronim tersebut tidak setrut dengan kaidah penyingkatan dan akronim dalam bahasa Indonesia. 


\section{DAFTAR PUSTAKA}

Arifin, E. Zaenal, Zulkarnain, Jumariam. 1992, Pemakaian Bahasa dalam Iklan Berita dan Papan Reklame. Jakarta; Pusat Pembinaan dan Pengembangan Bahasa, Departemen Pendidikan dan Kebudayaan.

Badan Pembinaan dan Pengembangan Bahasa, Kemendikbud. 2016. Ejaan Bahasa Indonesia. Jakarta: Badan Pembinaan dan Pengemabangan Bahasa.

Baryadi, I Praptomo. 2002. Dasar-Dasar Analisis Wacana dalam Ilmu Bahasa. Yogyakarta: Pustaka Gondho Suli.

Indiastini , Titik. 2016. "Wacana Iklan Lowongan Pekerjaan Di Harian Kedaulartan Rakyat". Prosiding Seminar Hasil Penelitian Kebahasaan dan Kesastraan. . Yogyakarta: CV. Azzagrafika

Jones, Russell. Editor. 2008. Loan-Words in Indonesian and Malay. Jakarta: Yayasan Obor. Pos Kota. 2016. "Rumah dijual”. Dalam Koran Pos Kota terbit tanggal 17 September, 2016. Jakarta: Pos Kota

.Sudaryanto. 2015. Metode dan Aneka Teknik Analisis Bahasa: Pengantar Penelitian Wahana Kebudayaan Secara Linguistis. Yogyakarta: Sanata Dharma University Press.

Tim Penyususun Kamus Besar Bahasa Indonesia. 2014. Kamus Besar Bahasa Indonesia. Edisi Keempat . Cetakan Ketujuh. Jakarta: Gramedia Pustaka Utama..

Wijana, Dewa Putu 1996. Dasar-Dasar Pragmatik, Yogyakarta: Andi.

Yunus, Abd. Rahman. 2016. "Adaptasi Kosakata Tertentu Serapan Bahasa Arab dalam Bahasa Indonesia". Prosiding Seminar Hasil Penelitian Kebahasaan dan Kesastraan. . Yogyakarta: CV. Azzagrafika. 